\title{
Synthesis of zeolite A using raw kaolin from Ethiopia and its application in removal of $\mathrm{Cr}$ (III) from tannery wastewater
}

Lijalem Ayele ${ }^{\mathrm{a}}$ Eduardo Pérez ${ }^{\mathrm{a}}$, Álvaro Mayoral ${ }^{\mathrm{b}}$, Yonas Chebude ${ }^{\mathrm{a}}$ and Isabel Díaz ${ }^{\mathrm{c}, *}$

${ }^{a}$ Chemistry Department, Addis Ababa University, P. O. Box 1176, Addis Ababa, Ethiopia

${ }^{b}$ Advanced Microscopy Laboratory (LMA), Nanoscience Institute of Aragon (INA), University of Zaragoza, Zaragoza, Spain.

${ }^{c}$ Instituto de Catálisis y Petroleoquímica, CSIC, c/Marie Curie 2, 28049 Madrid, Spain

*Corresponding author: idiaz@icp.csic.es

\begin{abstract}
BACKGROUND

The commercial production of zeolite A mainly involves costly synthetic chemicals. However, cheaper raw materials such as clay minerals, coal ashes, natural zeolites, solid wastes and industrial sludge have been tested. Based on this, the objective of present study is synthesis of zeolite A from two sources of raw kaolins (Ansho and Bombowha) from Ethiopia and evaluation of its application in tannery wastewater treatment.
\end{abstract}

\section{RESULTS}

The synthesis result indicated high crystallinity (> 90\%) of zeolite A using Ansho kaolin. Lower grade Bombowha kaolin yielded zeolite A with crystallinity of $80 \%$. In the tannery wastewater

This article has been accepted for publication and undergone full peer review but has not been through the copyediting, typesetting, pagination and proofreading process, which may lead to differences between this version and the Version of Record. Please cite this article as doi: $10.1002 /$ jctb.5334

This article is protected by copyright. All rights reserved. 
treatment study, a real sample having chromium concentration of $2036 \mathrm{mg} / \mathrm{L}$ was treated obtaining 99.8\% removal and about 200 mg/g adsorption capacity of Cr(III) using 100 g/L and 5 g/L adsorbent dose respectively. This indicated that the synthesized zeolite A has a great potential in Cr(III) removal from tannery wastewater.

\section{CONCLUSION}

In this study, zeolite A has been synthesized from two sources of kaolin from Ethiopia and has been evaluated in tannery wastewater treatment. The synthesis result indicated the formation of crystals of zeolite A with optimum crystallinity of $91 \%$ and the material exhibited chromium removal efficiency of $99.8 \%$.

Keywords: Zeolite A; kaolin; chromium; tannery wastewater

\section{Introduction}

The leather industry is becoming one of the major industrial sectors in Ethiopia that contributes substantially towards the national economy. According to the Ethiopian leather evaluation 2012 report, there were 26 tanneries in Ethiopia employing chrome tanning. ${ }^{1}$ Tanning process using chromium compounds is one of the most common methods for processing of hides due to the rapid processing, low cost, and better quality of the finished leather products. The function of chromium salts in tanning processes is to form a complex with the collagen to make it hydrothermally stable. ${ }^{2}$ In this process about $60-70 \%$ of chromium reacts with the hides, leaving about $30-40 \%$ of the chromium as waste. $^{3}$ The wastewater of tanning process is usually discharged, without proper treatment, into the sewerage system leading to one of the most recognized environmental problems in the leather industry. ${ }^{4}$

This article is protected by copyright. All rights reserved. 
In nature, chromium occurs in two major stable oxidation states: $\mathrm{Cr}(\mathrm{III})$ and $\mathrm{Cr}(\mathrm{VI})$. The tanning process is commonly carried out using $\mathrm{Cr}(\mathrm{III})$, and later on, the secondary treatment may generate $\mathrm{Cr}(\mathrm{VI})$ that causes adverse effects for the human health. Several methods have been used for removal of chromium from tannery wastewater: biological methods, membrane technologies, chemical precipitation, ion exchange, and adsorption., ${ }^{5,6}$ Some of these adsorbents and ion exchangers are activated carbon, fly ash, peat, recycled alum sludge, peanut hulls, resins, biomaterials, clay materials and zeolites. ${ }^{7-11}$ Along with the known ion exchangers, zeolites are worth of a special attention due to their high exchange capacity, reasonable costs and environmental compatibility. Natural and synthetic zeolites have been tested in the removal of Cr(III) removal from tannery wastewater. ${ }^{10,11}$ When a zeolite is used for environmental mitigation purposes, usually demands large amounts of adsorbent, therefore, it has to have a competitive price with respect to other technologies. For this reason, it is preferable to synthesize zeolites from more economical sources such as natural aluminosilicates. Covarrubias C et al. ${ }^{12}$ reported the synthesis of zeolite materials from kaolin and natural mordenites and their application for $\mathrm{Cr}(\mathrm{III})$ exchange. This study indicated that synthesized materials presented higher Cr(III) exchange capacity than commercial ones. Basaldella EI et al. ${ }^{13}$ also investigated the effect of $\mathrm{pH}$ changes on the ability of the synthetic zeolite A to remove $\mathrm{Cr}$ (III) from wastewater by ion exchange method. Their study demonstrated that the increase in $\mathrm{pH}$ during the ion exchange favored polymerization-precipitation of chromium species present in solution, which in turn, improved the metal removal capacity of zeolite A above the values expected for a pure cationic exchange reaction. Although different zeolite based materials have been used for the treatment of tannery wastewater, to our knowledge natural raw materials from Ethiopia have not yet been used in chromium removal from tannery wastewater. Therefore, the objective of the present

This article is protected by copyright. All rights reserved. 
work is to synthesize zeolite A using kaolin from Ethiopia and investigate its removal efficiency of $\mathrm{Cr}(\mathrm{III})$ from tannery wastewater collected from domestic tanneries.

\section{Experimental}

\section{Materials and methods}

Two raw kaolin samples: Ansho and Bombowha kaolins were collected from a local ceramic factory (Hawassa ceramic factory). Commercial zeolite A was purchased from Industrias Químicas del Ebro (Spain) for comparison. Analytical grade $\mathrm{NaOH}$ pellets was purchased from Sigma Aldrich and $98 \% \mathrm{CaCl}_{2} \cdot 6 \mathrm{H}_{2} \mathrm{O}$ from $\mathrm{BDH}$. Chromium wastewater was directly obtained from the research and development directorate of Leather Industry Development Institute (LIDI) of Ethiopia.

\section{Synthesis of zeolite A}

The synthesis of zeolite A was conducted using both raw and purified kaolins by hydrothermal and alkali fusion methods. ${ }^{14}$ In the purification of the raw kaolin, the physical method of purification which involves mechanical separation methods such as: sedimentation, ultrasonic suspension and magnetic separation have been used ${ }^{15}$. For the conventional hydrothermal synthesis; both raw and purified kaolins were used. The kaolin was first calcined at $600{ }^{\circ} \mathrm{C}$ for 3 h. Then, the alkaline treatment was done with $3 \mathrm{~mol} / \mathrm{L} \mathrm{NaOH}$ with stirring at $50{ }^{\circ} \mathrm{C}$ for $1 \mathrm{~h}$. For the synthesis involving alkali fusion method; the raw kaolin (1.25 g) was dry-mixed with $\mathrm{NaOH}$ (1.5 g) for $30 \mathrm{~min}$ followed by calcination at $600{ }^{\circ} \mathrm{C}$ during $1 \mathrm{~h}$. Then the calcined product was ground and mixed with $12.5 \mathrm{~mL}$ of water and stirred at $50{ }^{\circ} \mathrm{C}$ for $1 \mathrm{~h}$ for gel formation. In both

This article is protected by copyright. All rights reserved. 
methods, the gel formed undergoes aging at room temperature in static condition followed by crystallization for $3 \mathrm{~h}$ at $100{ }^{\circ} \mathrm{C}$. The reaction mixtures were filtered and washed with distilled water to remove excess alkali until the $\mathrm{pH}$ of the filtrate dropped below 10. Then, the samples were oven dried overnight at $80{ }^{\circ} \mathrm{C}$. For hydrothermal synthesis method, both raw and purified kaolins were used; products have been labelled as "R" and "P", respectively. For alkali fusion only raw kaolin was used and the final products were labelled with "F". "A" and "B" in the samples codes refers to the Ansho and Bombowha type of kaolins, respectively. Aging is indicated as $1 \mathrm{G}$ or $3 \mathrm{G}$ for the synthesis involving gel aging accordingly to the time spent (either 1h or 3h). The final label "3 h" refers to crystallization time.

\section{Characterization techniques}

Powder X-ray diffraction (XRD) patterns of the starting kaolin and synthetic zeolite A were collected with a Philips X'PERT diffractometer equipped with an X'Celerator detector and using $\mathrm{Cu} \mathrm{K} \alpha$ radiation. The morphology was studied by Scanning Electron Microscopy (SEM) using a NOVA NANO SEM 230 (FEI). Inductively Coupled Plasma Optical Emission Spectrometry (ICP-OES) Optima 3300 DV model was used to determine chemical weight percent composition of the samples. The Cation Exchange Capacity (CEC) of the Na-form of synthesized samples of zeolite A has been studied by GLP 22 multimeter Calcium ion selective electrode. Analytik Jena ZEEnit700 P model flame atomic absorption spectrophotometer (FAAS) was used to measure the concentration of chromium before and after adsorption experiment. Scanning transmission electron microscopy (STEM) was performed in a spherical aberration corrected ( $\mathrm{C}_{\mathrm{s}}$-corrected) FEI Titan XFEG, which was operated at $300 \mathrm{kV}$ equipped with a corrector for the electron probe allowing a maximum resolution of $0.8 \AA$. The microscope was also equipped with an EDS detector (EDAX) and a Gatan Tridiem energy filter.

This article is protected by copyright. All rights reserved. 


\section{Chromium (III) adsorption experiments}

Adsorption experiments were carried out in batch mode at a temperature of $25 \pm 0.5{ }^{\circ} \mathrm{C}$, with continuous stirring at $500 \mathrm{rpm}$. A total of $10 \mathrm{~mL}$ of wastewater was treated with varying adsorbent dosage from $2 \mathrm{~g} / \mathrm{L}$ to $100 \mathrm{~g} / \mathrm{L}$ and a total contact time of $24 \mathrm{~h}$. All mixing vessels were kept sealed throughout the duration of each test in order to minimize evaporation of water. Control experiments were carried out in the absence of adsorbent. All samples were filtered prior to analysis. The first few milliliters of the filtered samples were discarded in order to minimize the effect of any adsorption that may occur on the filter paper. The $\mathrm{pH}$ of all the samples was measured, but the solution was not buffered. The adsorbed chromium was determined by mass balance according to the following equation 1 :

$$
\% \text { Cr Removal }=\frac{C_{0}-C_{e}}{C_{0}} \times 100
$$

Where; $C_{o}$ and $C_{e}$ are the concentration of $\mathrm{Cr}(\mathrm{III})$ in the sample solution before and after the treatment (when equilibrium is achieved).

Adsorption capacity $\left(q_{e}\right)$ which is defined as the amount of adsorbate retained per mass of adsorbent was calculated using the following expression 2:

$$
q_{e}=\frac{\left(C_{e}-C_{0}\right) V}{m}
$$

Where $V$ is the volume of solution treated and $m$ the mass of adsorbent utilized.

This article is protected by copyright. All rights reserved. 


\section{Kinetic study of the removal of $\mathrm{Cr}$ (III) from tannery wastewater}

The kinetic study for $\operatorname{Cr}(\mathrm{III})$ removal from tannery wastewater was carried out in batch with different contact times at room temperature and fixing the dosage rate to $25 \mathrm{~g} / \mathrm{L}$ (1.25 g in 50 $\mathrm{mL}$ ). Samples of the treated wastewater were collected at different time intervals (from 10 to $2880 \mathrm{~min}$ ), then the solid phase was separated by filtration through a Whatman filter paper and the filtrate was analyzed for chromium.

\section{Results and discussion}

\section{Synthesis of Zeolite A}

The X-ray diffraction patterns of the starting raw Ansho and Bombowha kaolins, metakaolins and synthetic products are depicted in Figure 1. Profiles labelled as (a) show the XRD profiles of the raw kaolins indicating the presence of kaolinite $(\mathrm{K})$, having a layered structure with $\mathrm{d}_{100}$ at $12.34^{\circ}$ and $\mathrm{d}_{200} 24.64^{\circ}$, and the characteristic diffraction intensity of quartz (Q) and Mica (M) at $2 \theta$ value of 26.6 and $8.9^{\circ}$, which are the common impurities found in kaolins. Profiles (b) show the XRD patterns of metakaolin formed after calcination at $600{ }^{\circ} \mathrm{C}$ for $3 \mathrm{~h}$ exhibiting the disappearance of the diffraction peaks of kaolin, accompanied by the appearance of amorphous aluminosilicate (a broad featureless bulge extends between $2 \theta$ of 15 to $40^{\circ}$ ), which is the characteristic X ray diffraction pattern of metakaolin. ${ }^{16}$ Profiles (c) show the synthetic zeolites obtained using $3 \mathrm{~mol} / \mathrm{L}$ concentration of $\mathrm{NaOH}$. The XRD profiles of the synthetic sample fit well to the profile of the commercial zeolite A (profile d, dotted line) and the literature value, ${ }^{17}$ although the presence of traces of Quartz could be detected in the patterns. The percentage

This article is protected by copyright. All rights reserved. 
crystallinity data (\% $\left.\mathrm{C}_{\mathrm{XRD}}\right)$ calculated by comparing the sum of the five most intense peaks $\left(\mathrm{d}_{442}\right.$ at $21.67^{\circ}, \mathrm{d}_{622}$ at $23.99^{\circ}, \mathrm{d}_{642}$ at $27.11^{\circ}, \mathrm{d}_{820}$ at $29.94^{\circ}$ and $\mathrm{d}_{664}$ at $34.18^{\circ}$ ) using the commercial zeolite A (CZA) as reference are compiled in Table 1. Optimum crystallinity of 91\% was attained by the synthesis involving alkali fusion using raw Ansho kaolin, A-F-3M-3G-3h most probably due to the major conversion of the quartz into zeolite A using this method. Comparable crystallinity of $90 \%$ was also achieved using purified Ansho kaolin in the conventional hydrothermal synthesis method, A-P-3M-3G-3h. For the low grade Bombowha kaolin, optimum crystallinity of $84 \%$ was attained using alkali fusion with raw kaolin, B-F-3M-1G-3h. The conventional hydrothermal synthesis method revealed optimum crystallinity of $75 \%$ with the purified kaolin, B-P-3M-1G-3h. For both types of kaolins, purification of the starting kaolin resulted in the improvement in the crystallinity of the final zeolite A regardless of the method used, due to the efficient removal of Mica and Quartz. ${ }^{15}$ The effect of aging time (1G and 3G) in the final quality is also evidenced by the data in Table 1 . Moreover, for the same synthesis method, regardless of the type of kaolins and purification, the aging step enhances the crystallinity of the final zeolite A once again due to the efficient incorporation of the remaning traces of Quartz as part of the zeolite. For Ansho kaolin based synthetic products: A-F-3M-3G3h and A-P-3M-3G-3h, the SEM (Figure 2) confirmed the typical cubic shaped crystals of zeolite A with rounded edges with an average particle size of $3.0 \mu \mathrm{m}$. However, for Bombowha kaolin based synthetic products: B-F-3M-1G-3h and B-P-3M-1G-3h, slightly sharp edges of cubic crystals of zeolite A having average particle size of $3.0 \mu \mathrm{m}$ (Figure 2). The ICP-OES analyses indicated $\mathrm{Si} / \mathrm{Al}=1$ for the best synthetic products for both types of kaolins (Table 1 ). The table also includes the cation exchange capacity (CEC) results which revealed optimum calcium exchange capacity in those samples with highest crystallinity. Given the requirements of

This article is protected by copyright. All rights reserved. 
the market, the best synthetic products (A-F-3M-3G-3h, A-R-3M-3G-3h, A-P-3M-3G-3h and BF-3M-1G-3h) were tested in detergent formulation following the commercial method implemented by Ethiopian detergents manufacturers. ${ }^{18}$ However, for this particular chromium removal work, the requirements in the quality of the final zeolite are not crucial, thus a low quality zeolite A obtained from the low grade type Bombowha kaolin (B-R-3M-3h) was used trying to add value to a cheap low quality material. ${ }^{14}$ The synthetic product exhibited low crystallinity of 64\% and its morphological analysis from SEM (Figure 3) shows the formation of cubic crystals of zeolite having sharp edges in comparison with the rounded edges of crystals of the commercial zeolite A. The ICP elemental analysis result of the synthetic zeolite A shows a $\mathrm{Si} / \mathrm{Al}=1.1$, which is in a good agreement with the $\mathrm{Si} / \mathrm{Al}$ ratio of commercial zeolite $\mathrm{A}(\mathrm{Si} / \mathrm{Al}=$ 1). This in turn results in a maximum content of sodium ions which can be easily exchanged for chromium cations and its removal to the minimum limit.

\section{Adsorption results}

For the present study, the collected tannery wastewater contains Cr(III) concentration of 2036 $\mathrm{mg} / \mathrm{L}$. This indicates that the concentration of chromium in the wastewater is higher than 1000 fold to its maximum limits that could be released into the environment so it needs great attention from health and environmental aspects.

\section{Effect of adsorbent dosage}

The effect of adsorbent dosage on the removal of chromium from the tannery wastewater is plotted in Figure 4. The results indicated that the adsorption efficiency increase with the increments in the dose from 2 to $100 \mathrm{~g} / \mathrm{L}$ keeping temperature $\left(25^{\circ} \mathrm{C}\right)$ and contact time $(24 \mathrm{~h})$ constant. Maximum removal was observed with adsorbent dose of $100 \mathrm{mg} / \mathrm{L}$. Increasing the

This article is protected by copyright. All rights reserved. 
percentage of adsorption with adsorbent dose is expected given the increase in adsorbent surface area and availability of more adsorption sites. ${ }^{19}$ However, the adsorption capacity $\left(q_{e}\right)$ decreases while increasing the adsorbent dosage. The drop in adsorption capacity while increasing the adsorbent dose can be attributed to adsorption sites that remain unsaturated since the number of available adsorption sites has increased. ${ }^{20}$ The variation of $\mathrm{pH}$ slightly increased from initial $\mathrm{pH}$ 4 to $\mathrm{pH} 4.5-4.7$ for the adsorbent doses of $2 \mathrm{~g} / \mathrm{L}$ and $100 \mathrm{~g} / \mathrm{L}$. This insignificant $\mathrm{pH}$ change from the lower adsorbent dosage to the higher adsorbent dosage eliminates the possibility of $\mathrm{Cr}(\mathrm{III})$ removal mechanism by polymerization-precipitation as suggested by Basaldella EI et al. ${ }^{13}$

\section{Adsorption kinetics}

Adsorption kinetics describes the solute uptake rate as a function of the contact time of the adsorbate on the adsorbent. Kinetics of adsorption is shown in Figure 5 as adsorption capacity at different contact times. The experimental results showed rapid initial adsorption rate for the first $3 \mathrm{~h}$ followed by a slower rate until an asymptote is reached at about $q_{t}=80 \mathrm{mg} / \mathrm{g}$. A similar trend has been reported by Choudhury TR et $\mathrm{al}^{21}$. in which there was no significant change in equilibrium concentration after $6 \mathrm{~h}$ for the adsorption of $\operatorname{Cr}(\mathrm{III})$ from aqueous solution by groundnut shell. Further contact time (48 h adsorption) did not give significant change which indicates the equilibrium point is attained. Adsorption kinetics was modeled by several kinetic models ${ }^{22}$. The experimental data fitted best to a pseudo-second order kinetics, where the rate of adsorption is proportional to the square of the driving force, that is the difference between the adsorption capacity at a time $t, q_{t}$ and the adsorption capacity at infinite time, or at equilibrium $q_{e}:$

$\frac{d q_{t}}{d t}=k_{2}\left(q_{e}-q_{t}\right)^{2}$

This article is protected by copyright. All rights reserved. 
The fitting yielded the parameters: kinetic constant: $k_{2}=3.6 \times 10^{-3} \mathrm{~g} \mathrm{mg}^{-1} \mathrm{~h}^{-1}$ and adsorption capacity at $t=\infty, q_{e}=82.3 \mathrm{mg} / \mathrm{g}$

\section{Adsorption isotherm and adsorption mechanism}

Adsorption data are usually described by adsorption isotherms which relate adsorption capacity $\left(q_{e}\right)$ to the equilibrium adsorbate concentration in the bulk fluid phase $\left(C_{e}\right)$. Figure 6 shows a representation of $q_{e}$ versus $C_{e}$ for the adsorption of $\mathrm{Cr}(\mathrm{III})$ onto the zeolite A synthesized from kaolin (B-R-3M-3h), and onto commercial zeolite A for comparison. Both adsorption isotherms show an S-shape and present asymptotes at ca. $200 \mathrm{mg} / \mathrm{g}$. At moderate $C_{e}$, commercial zeolite displays significantly higher adsorption capacities, which is consistent to higher crystallinity, but for the highest equilibrium concentrations (low dosage rates), the curves seem to converge and present similar $q_{e}$ values.

However, the equilibrium data did not fit to any of the models proposed in the literature. Moreover, the S-shape of the graphics is very unusual for adsorption processes indicating the coexistence of different mechanisms of $\mathrm{Cr}$ removal. In addition, from the theoretical cation exchange capacity (CEC) of $\mathrm{Na}$ form of this zeolite $\mathrm{A}$, the expected maximum adsorption capacity for $\mathrm{Cr}(\mathrm{III})$ is about $95 \mathrm{mg} / \mathrm{g}$ of zeolite. However, the experimental result obtained indicated that the $\mathrm{Cr}(\mathrm{III})$ adsorption capacity was about $200 \mathrm{mg} / \mathrm{g}$ at the lower adsorption doses (Figure 4). This unexpected high adsorption capacity attained at the lower adsorbent dose was further investigated by studying the XRD pattern of $\mathrm{Cr}(\mathrm{III})$ exchanged zeolite $\mathrm{A}$ in order to verify whether the zeolite remains stable or whether it collapses leading to pure surface adsorption. The XRD profiles of the zeolite A recovered after the adsorption experiment at different adsorbent doses are shown in Figure 7. The XRD results indicate that at lower dosages (5 and $10 \mathrm{~g} / \mathrm{L}$ ) the synthetic zeolite A loses its crystallinity. This situation may favor the co-

This article is protected by copyright. All rights reserved. 
precipitation of $\mathrm{Cr}(\mathrm{III})$ in the form of chromium silicate, $\mathrm{Cr}_{2}\left(\mathrm{SiO}_{3}\right)_{3}$ or other amorphous solid material that augmented an apparent adsorption capacity of the lower adsorbent doses up to 200 mg/g. However, for the higher adsorbent doses (25, 50, 75 and $100 \mathrm{~g} / \mathrm{L}$ ), the XRD profile shows the zeolite remained crystalline after chromium removal experiment. Moreover, from Figure 4 it is possible to see that the adsorption capacities for the higher adsorbent doses are less than the theoretical cation exchange capacity $(95 \mathrm{mg} / \mathrm{g}$ ). So it is possible to say the removal mechanism is merely due to ion exchange for the higher adsorbent doses. As the dosage rate is smaller, $C_{e}$ is higher and the values of $q_{e}$ for both curves become similar to each other, which can be explained if the adsorption does no longer depend on ion exchange but probably on precipitation of $\mathrm{Cr}_{2}\left(\mathrm{SiO}_{3}\right)_{3}$ or other species.

The situation observed for the synthetic zeolite A is also true for the commercial zeolite A used in the $\operatorname{Cr}(\mathrm{III})$ removal from tannery wastewater. The XRD analysis of the low dosage (5 g/L) indicated the absence of the characteristic peaks of zeolite A (Figure 8). For the higher doses (25, 50 and $100 \mathrm{~g} / \mathrm{L}$ ), zeolite A survived to the adsorption of $\operatorname{Cr}(\mathrm{III})$. Hence, the higher adsorption capacity attained at the lower adsorbent doses for both synthetic and commercial zeolite A verified that the removal mechanism is not merely ion exchange. Pansini $\mathrm{M}$ et $\mathrm{al}^{10}$. similarly reported structural collapse during chromium removal from wastewater by ion exchange using zeolitic rock containing phillipsite and chabazite. Their assumption for the structural collapse may be caused in some instances by the unfavorable environment determined by the presence of Brønsted acid and may be also due to the framework-cation interaction.

The relative percent crystallinities $\left(\mathrm{C}_{\mathrm{XRD}}\right)$ calculated for zeolite $\mathrm{A}$ after adsorption experiments are summarized in Table 2. The data from the table shows that as the adsorbent dose increases, the crystallinity increases for both synthetic and commercial zeolite A. Further electron This article is protected by copyright. All rights reserved. 
microscopy studies were carried out in order to understand the adsorption of chromium by the synthetic zeolite A. Spherical aberration $\left(\mathrm{C}_{\mathrm{s}}\right)$ corrected Scanning Transmission Electron Microscopy coupled with High Angular Annular Dark Field detector $\left(\mathrm{C}_{\mathrm{s}}\right.$-corrected STEMHAADF) instead of conventional $\mathrm{TEM}^{23}$ was chosen due to the high analytical power of this mode, while maintaining atomic resolution using the $\mathrm{C}_{\mathrm{s}}$ corrector in the condenser system. Besides, it has to be mentioned that low silica zeolite like zeolite A is extremely unstable under the electron beam ${ }^{24}$ due to the large amount of water contained in the structure. Thus; a precise control on the exposure to the electron beam has to be taken into account. Figure 9 shows $\mathrm{C}_{\mathrm{s}}-$ corrected STEM-HAADF images of the synthetic zeolite A. The image shows the perfectly arranged structure of zeolite matching with the overlaid model (representing in blue the "T" atoms, $\mathrm{Si}$ and $\mathrm{Al}$ ). The dark contrast in this mode corresponds to the parts of the material with no electron density, i.e., zeolite alpha cages, linked to each other by sodalite cages, in which the four member rings can be clearly observed in brighter contrasts. The zeolitic framework of the chromium ion-exchanged material (Figure 10) is exactly the same, meaning that in this particular sample $(100 \mathrm{~g} / \mathrm{L})$ the crystallinity of the zeolite A remains stable. The EDS spectrum, which displays the composition of $\mathrm{Cr}$-exchanged zeolite A shows the presence of $\mathrm{Cr}$ in addition to the zeolite framework elements $(\mathrm{O}, \mathrm{Si}, \mathrm{Al}, \mathrm{Na})$ which corroborates the absorption of chromium. However, it is not possible to observe any contrast inside the cages, probably due to the low amount of $\mathrm{Cr}$ atoms that do not yield sufficient electron density to inverse the contrast.

\section{Conclusion}

In this work, the synthesis of zeolite A using kaolin from Ethiopia and evaluation of its application in the removal of chromium from tannery wastewater was undertaken. The synthesis of zeolite A has conducted by the conventional hydrothermal synthesis and alkali fusion methods

This article is protected by copyright. All rights reserved. 
using both raw and purified kaolins. For this particular tannery wastewater treatment, the lowest quality type of zeolite A made from the low grade raw type kaolin has been used. Based on this, the removal of $\operatorname{Cr}(\mathrm{III})$ from tannery wastewater having initial concentration of $2036 \mathrm{mg} / \mathrm{L}$ was conducted. The study result shows maximum removal of $99.8 \%$ with adsorbent dose of $100 \mathrm{~g} / \mathrm{L}$ and adsorption capacity of $200 \mathrm{mg} / \mathrm{g}$ was obtained by adsorbent dose of $5 \mathrm{mg} / \mathrm{L}$. The kinetics study result indicated that the maximum adsorption was attained in the first $3 \mathrm{~h}$ adsorption and the experimental data fitted best to pseudo-second order kinetics. Moreover, the adsorption isotherm data could not fit to any of the adsorption models probably due to the different removal mechanism attained at different adsorbent doses.

\section{Acknowledgments}

This work has been funded through the Project MAT2016-77496-R (AEI/FEDER, UE). ID acknowledges the CSIC for a research leave at AAU. The Chemistry Department, Addis Ababa University is also acknowledged for financial support. Directorate of Leather Industry Development Institute (LIDI) of Ethiopia is acknowledged for supplying the tannery wastewater.

\section{References}

1. Boario M. Technical assistance project for the upgrading of the Ethiopian leather and leather products industry, UNIDO, Vienna, PP 1-105 (2012).

2. Anthony D. Covington (2009); Tanning chemistry: The science of leather.

3. Sreeram KJ and Ramasami $\mathrm{T}$, Sustaining tanning process through conservation, recovery and better utilization of chromium. Resour Conserv Recy 38: 185-212 (2003).

This article is protected by copyright. All rights reserved. 
4. Belay AA, Impacts of Chromium from Tannery Effluent and Evaluation of Alternative Treatment Options. J Environ Protect 01: 53-58 (2010).

5. Ghosh P, Kumar R, Samanta AN and Ray S, Decontamination of tannery industry wastewater containing high organic load along with $\mathrm{Cr}^{3+}$ : a comparative study. Asia Pac J Chem Eng 8: 645656 (2013).

6. Zayed A and Terry N, Chromium in the environment: factors affecting biological remediation. Plant Soil 249: 139-156 (2003).

7. Abass EA and Reza V, Chromium (III) Removal and Recovery from Tannery Wastewater by Precipitation Process. Am J Appl Sci 2: 1471-1473 (2005).

8. Fahim NF, Barsoum BN, Eid AE and Khalil MS, Removal of chromium(III) from tannery wastewater using activated carbon from sugar industrial waste. J Hazard Mater 136: 303-309 (2006).

9. Gupta VK, Carrott PJM, Ribeiro Carrott MML and Suhas, Low-Cost Adsorbents: Growing Approach to Wastewater Treatment. Crit Rev Env Sci 39: 783-842 (2009).

10. Pansini M, Colella C, De Gennaro M, Chromium removal from water by ion exchange using zeolite. Desalination 83: 145-157 (1991).

11. Covarrubias C, Arriagada R, Yáñez J, García R, Angélica M, Barros SD, Arroyo P and SousaAguiar FE, Removal of chromium (III) from tannery effluents, using a system of packed columns of zeolite and activated carbon. J Chem Technol Biotechnol 80: 899-908 (2005).

12. Covarrubias C, García R, Arriagada R, Yánez J and Garland MT, Cr(III) exchange on zeolites obtained from kaolin and natural mordenite. Micropor Mesopor Mater 88: 220-231 (2006).

13. Basaldella EI, Vázquez PG, Iucolano F and Caputo D. Chromium removal from water using LTA zeolites: Effect of pH. J Colloid Interface Sci 313: 574-578 (2007).

14. Ayele L, Pérez-Pariente J, Chebude Y and Díaz I, Conventional versus alkali fusion synthesis of zeolite A from low grade kaolin. Appl Clay Sci 132-133: 485-490 (2016).

15. Ayele L, Pérez-Pariente J, Chebude Y and Díaz I, Synthesis of Zeolite A from Ethiopian kaolin. Micropor Mesopor Mater 215: 29-36(2015).

16. Mitra BB and Bhattacherjee S, X-Ray diffractions studies on the transformation of kaolinite into metakolin: I. Variabiltiy of interlayer spacings. Am Miner 54: 1408-1418 (1969).

17. Treacy MM and Higgins JB, Collection of Simulated XRD Powder Patterns for Zeolites, 4th ed. Elsevier Science Publishers, Amsterdam, pp 212-213 (2001).

This article is protected by copyright. All rights reserved. 
18. Ayele L, Perez-Pariente J, Chebude Y and Diaz I, Synthesis of zeolite A using kaolin from Ethiopia and its application in detergents. New J Chem 40: 3440-3446 (2016).

19. Wanees SA, Ahmed AMM, Adam MS and Mohamed MA, Adsorption Studies on the Removal of Hexavalent Chromium-Contaminated Wastewater using Activated Carbon and Bentonite.

\section{Chem J 2: 95-105 (2012).}

20. Ayaliew Werkneh AA and Beyene HD. Removal of hexavalent chromium from tannery wastewater using activated carbon primed from sugarcane bagasse:Adsorption/desorption studies. Am J Appl Chem 2: 128-135 (2014).

21. Choudhury TR, Pathan KM, Amin MN, Ali M, Quraishi SB, Mustafa AI, Adsorption of Cr(III) from aqueous solution by groundnut shell. J Env Sci Water Res 1: 144-150 (2012).

22. McKay G. The Adsorption of basic dye onto silica from aqueous solution-solid diffusion model. Chem Eng Sci 39: 129-138 (1984).

23. Mayoral A, Coronas J, Casado C, Tellez C, Díaz I, Atomic Resolution Analysis of Microporous Titanosilicate ETS-10 through Aberration Corrected STEM Imaging. Chem Cat Chem 5: 25952598 (2013).

24. Mayoral A, Carey T, Anderson PA, Diaz I, Atomic resolution analysis of porous solids: A detailed study of silver ion-exchanged zeolite A. Micropor Mesopor Mater 166: 117-122 (2013).

This article is protected by copyright. All rights reserved. 
Table 1. Percent crystallinity (\% $\mathrm{C}_{\mathrm{XRD}}$ ), Si/Al ratio determined by ICP-OES elemental analysis and calcium exchange capacity (CEC) of synthetic zeolite A.

\begin{tabular}{l|c|c|c}
\hline Sample & \% C $\mathbf{X R D}$ & Si/Al & $\begin{array}{c}\text { CEC } \\
\left.\text { (mg CaCO }_{3} / \mathbf{g}\right)\end{array}$ \\
\hline A-F-3M-3G-3h & 91 & 1.0 & 310 \\
A-P-3M-3G-3h & 90 & 1.0 & 295 \\
A-R-3M-3G-3h & 74 & 1.0 & 290 \\
A-P-3M-3h & 72 & 1.1 & 280 \\
A-R-3M-3h & 62 & 1.1 & 160 \\
B-F-3M-1G-3h & 84 & 1.0 & 300 \\
B-P-3M-1G-3h & 75 & 1.0 & 250 \\
B-R-3M-1G-3h & 66 & 1.1 & 230 \\
B-P-3M-3h & 68 & 1.1 & 190 \\
B-R-3M-3h & 64 & 1.1 & 150 \\
\hline
\end{tabular}

This article is protected by copyright. All rights reserved. 
Table 2. Percent crystallinity ( $\mathrm{C}_{\mathrm{XRD}}$ ) of ZA (B-R-3M-3h) and commercial zeolite A (CZA) after $\operatorname{Cr}(\mathrm{III})$ removal.

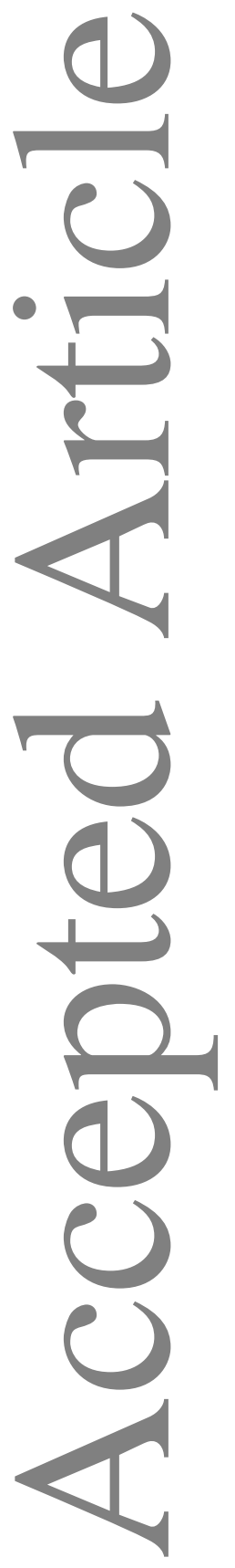

\begin{tabular}{ccc}
\hline \multirow{2}{*}{ Adsorbent dose (g/L) } & \multicolumn{2}{c}{$\mathbf{C}_{\text {XRD }}$ (\%) } \\
\cline { 2 - 3 } & B-R-3M-3h & CZA \\
\hline 100 & 40 & 25 \\
75 & 34 & - \\
50 & 25 & 24 \\
25 & 19 & 17 \\
10 & 9 & - \\
5 & - & - \\
\hline
\end{tabular}

This article is protected by copyright. All rights reserved. 


\section{FIGURE CAPTIONS}

Figure 1. XRD patterns of Ansho (A) and Bombowha (B) raw kaolins(a), Metakaolins(b), synthetic zeolite A(c) and commercial zeolite A(d).

Figure 2. SEM micrographs of the synthetic zeolite A from Ansho (A) and Bombowha (B) kaolins by alkali fusion (F) and conventional (P) hydrothermal synthesis at different aging times.

Figure 3. SEM micrographs of synthetic zeolite A (B-R-3M-3 h) and commercial zeolite A (CZA).

Figure 4. Cr(III) removal from tannery wastewaters using synthetic zeolite A (B-R-3M-3h).

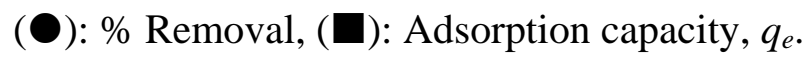

Figure 5. Adsorption kinetics for $\mathrm{Cr}(\mathrm{III})$ removal using synthetic zeolite A (B-R-3M-3h).

Figure 6. Adsorption isotherm for $\mathrm{Cr}(\mathrm{III})$ removal by synthetic zeolite A (一- - ) and by commercial zeolite A (-- $\square--)$.

Figure 7. XRD patterns of synthetic zeolite A (B-R-3M-3h) after adsorption experiment with different doses; (a) 5 g/L (b) 10 g/L (c) 25 g/L (d) 50 g/L (e) 75 g/L and (f) 100 g/L.

Figure 8. XRD patterns of commercial zeolite A after adsorption experiment with different adsorbent doses: (a) 5 g/L (b) 25 g/L (c) $50 \mathrm{~g} / \mathrm{L}$ (d) $100 \mathrm{~g} / \mathrm{L}$.

Figure 9. Cs-corrected STEM-HAADF images of synthetic zeolite A (B-R-3M-3h).

Figure 10. Cs-corrected STEM-HAADF images and EDS spectrum of $\mathrm{Cr}(\mathrm{III})$ exchanged synthetic zeolite A (B-R-3M-3h).

This article is protected by copyright. All rights reserved. 
Figure 1. XRD patterns of Ansho (A) and Bombowha (B) raw kaolins (a), Metakaolins (b), synthetic zeolite A (c) and commercial zeolite A (d).
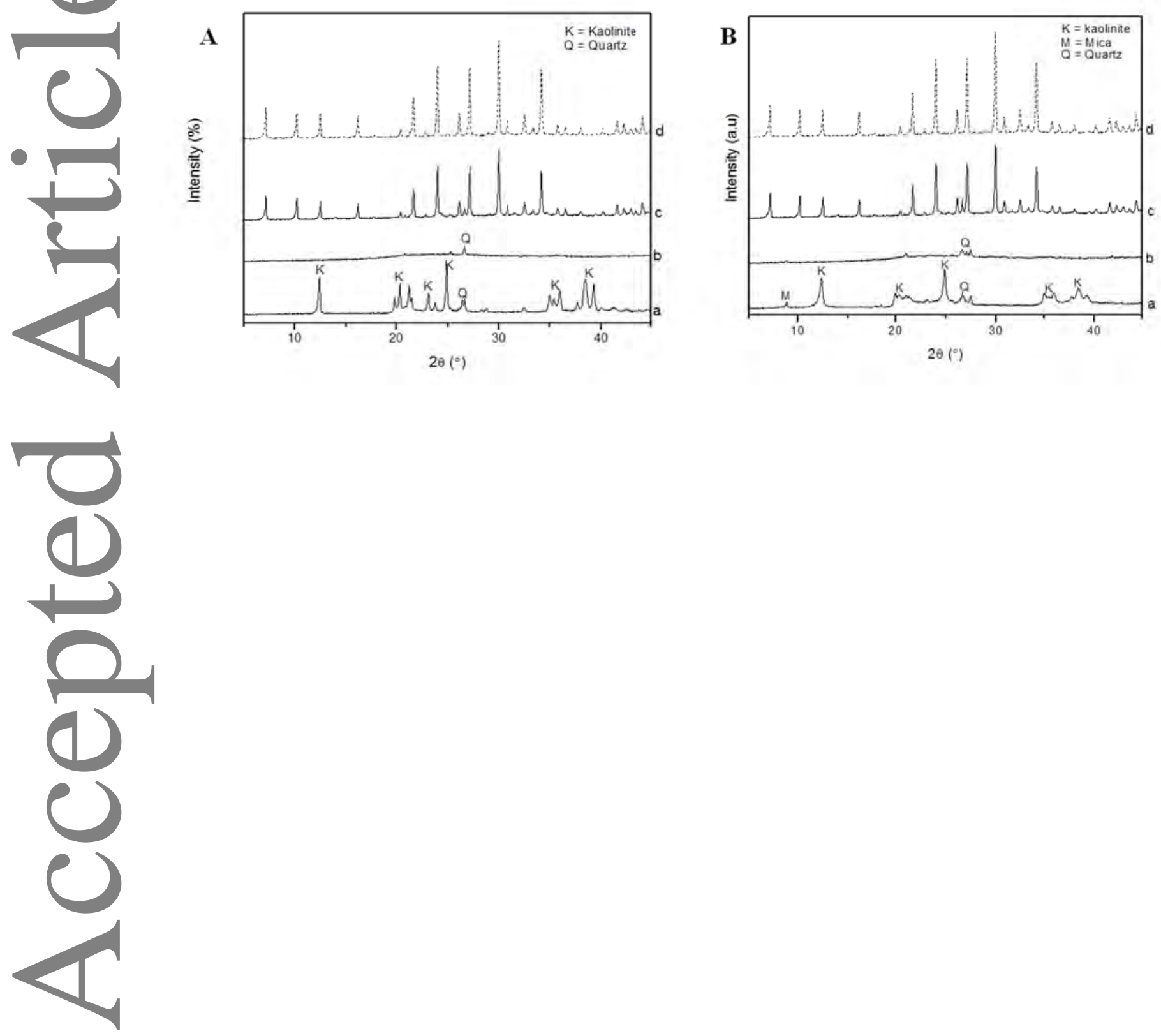

This article is protected by copyright. All rights reserved. 
Figure 3. SEM micrographs of zeolite A (B-R-3M-3 h) and commercial zeolite A (CZA)
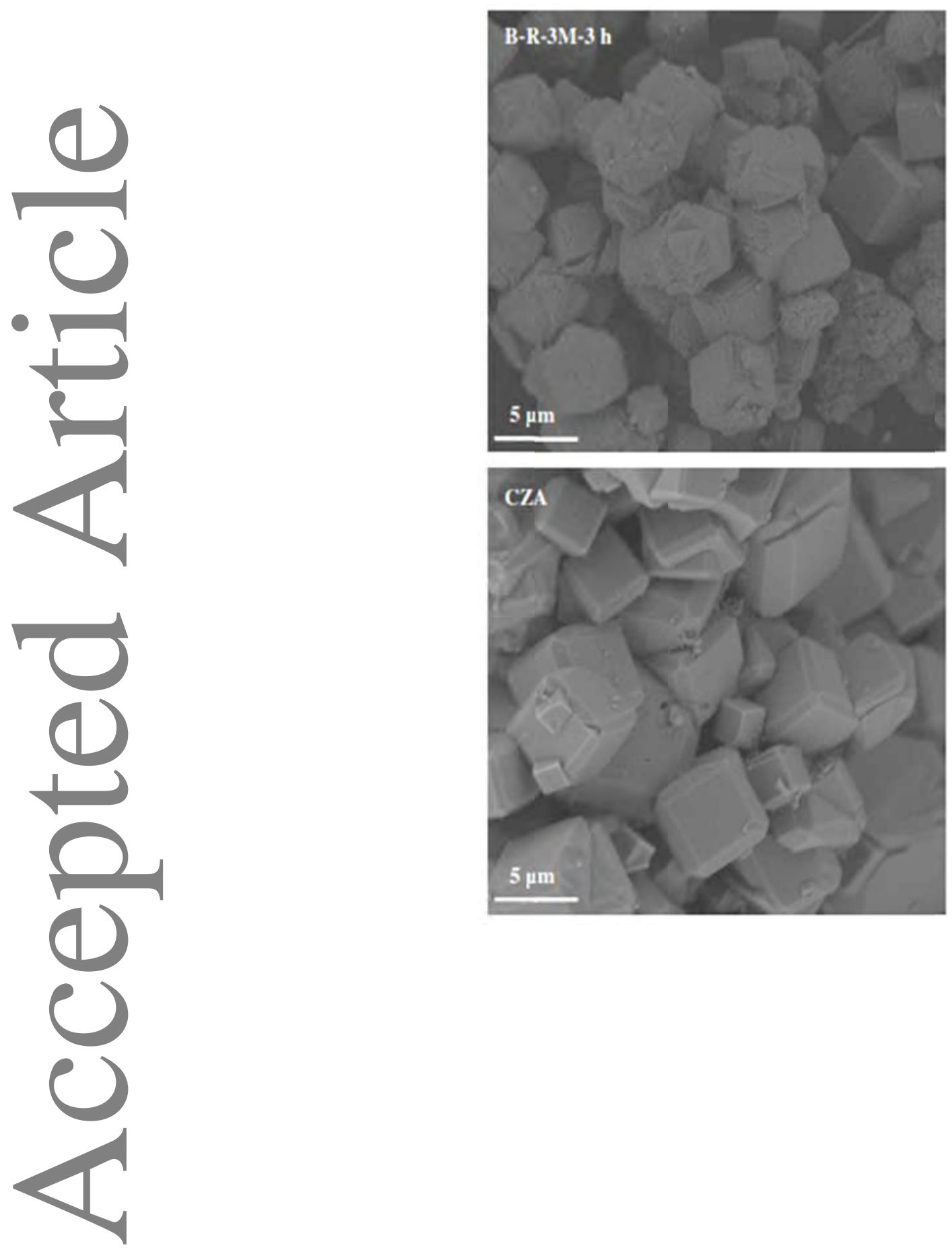

This article is protected by copyright. All rights reserved. 
Figure 6. Adsorption isotherm for $\mathrm{Cr}(\mathrm{III})$ removal by synthetic zeolite $\mathrm{A}(-\mathbf{\square}-$ ) and by commercial zeolite A (-- $\square--)$.
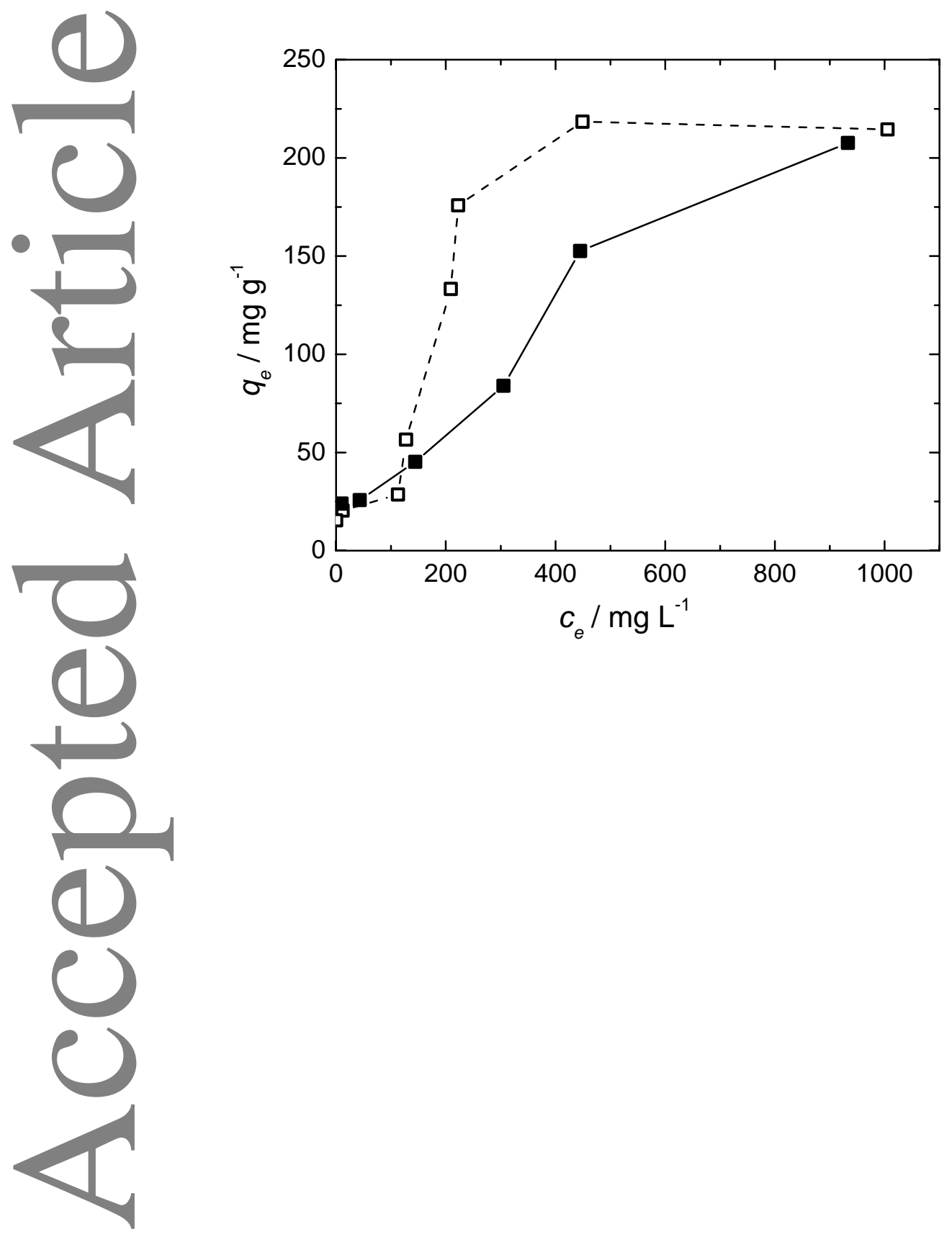

This article is protected by copyright. All rights reserved. 
Figure 7. XRD patterns of synthetic zeolite A (B-R-3M-3h) after adsorption experiment with different doses; (a) 5 g/L (b) 10 g/L (c) 25 g/L (d) 50 g/L (e) 75 g/L and (f) 100 g/L
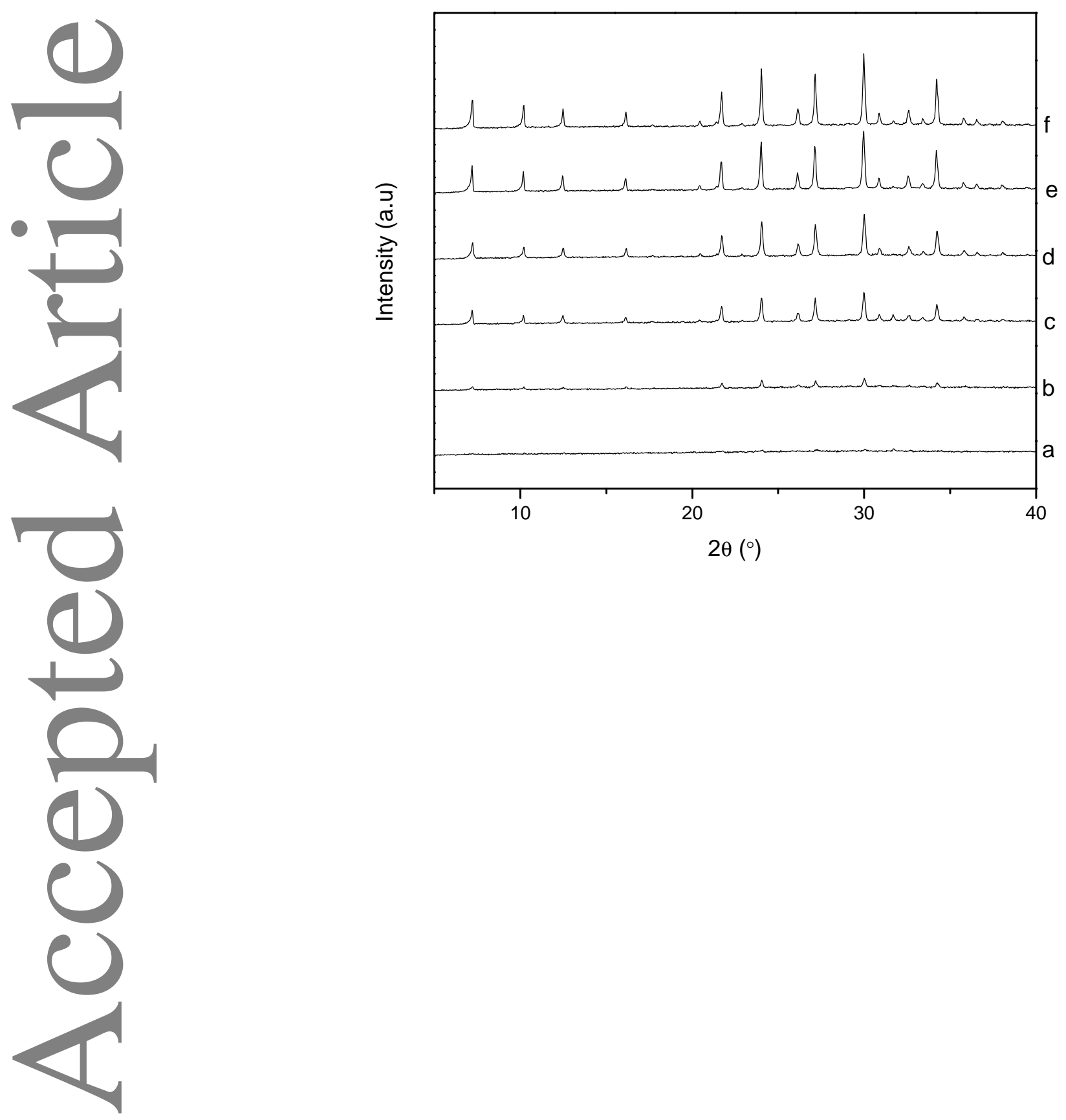

This article is protected by copyright. All rights reserved. 
Figure 9. Cs-corrected STEM-HAADF images of synthetic zeolite A (B-R-3M-3h)
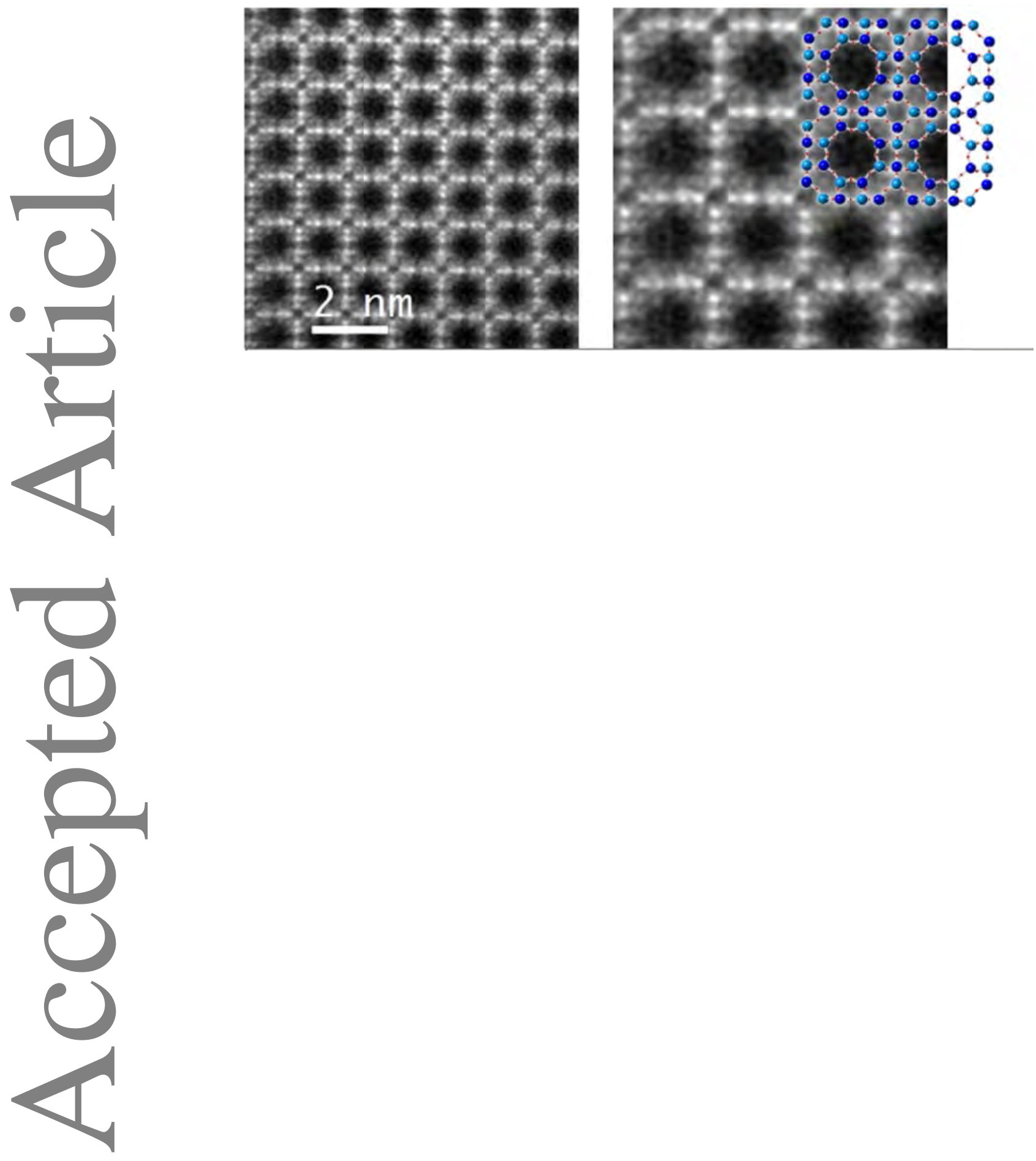

This article is protected by copyright. All rights reserved. 
Figure 10. Cs-corrected STEM-HAADF images and EDS spectrum of Cr(III) exchanged synthetic zeolite A (B-R-3M-3h)
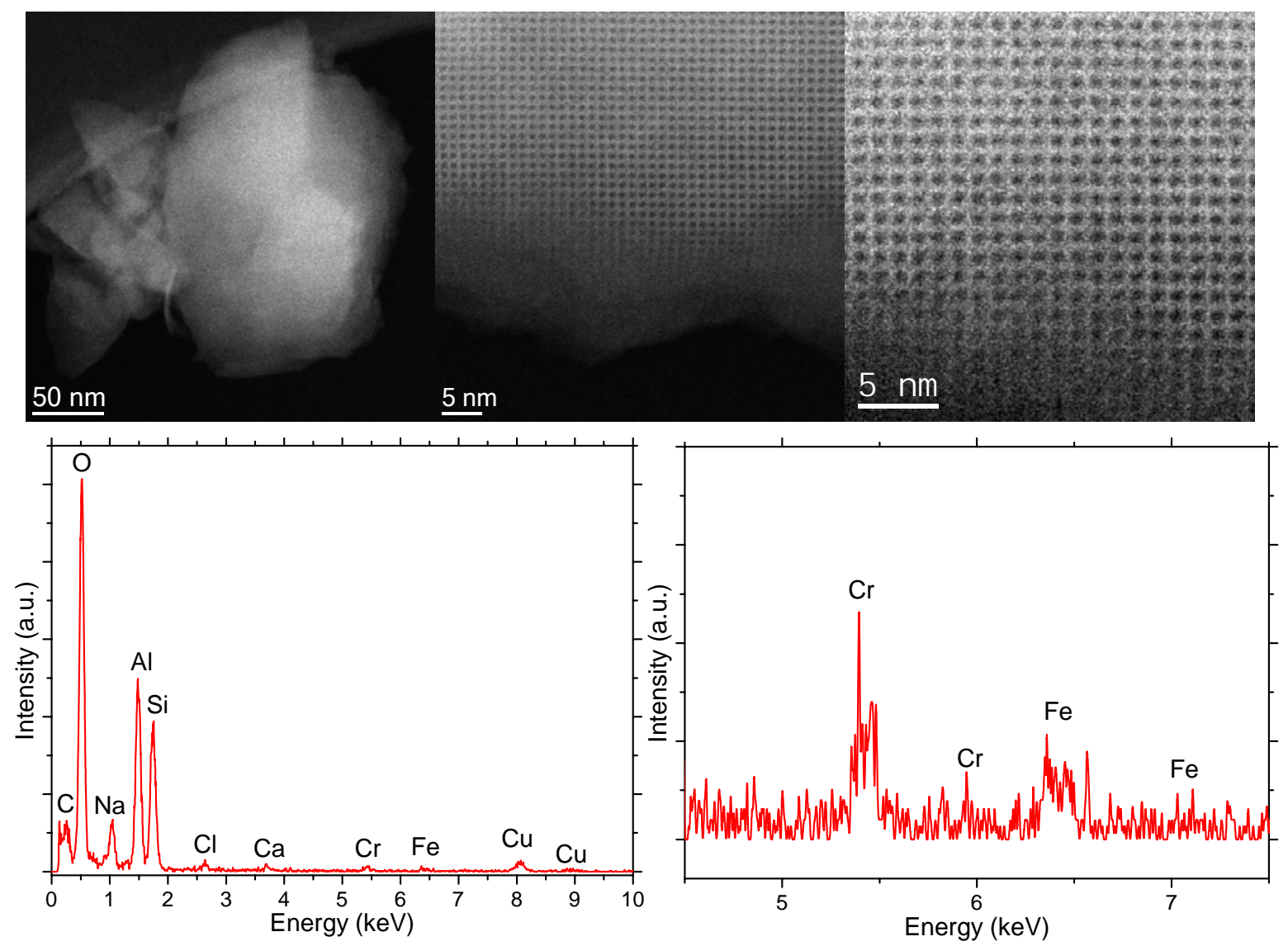

This article is protected by copyright. All rights reserved. 